\title{
التقييم التغذوي للبالغين في مرحلتي أواسط العمر والثيخوخة وعلاقتها ببعض العوامل في محافظة الإحساء، شرق المملكة العربية السعودية وعلية
}

\author{
نجاة علي العباد \\ قسم علوم الغذاء و التغذية بكلية العلوم الزر اعية والأغذية - جامعة الملك فيصل - الملكة العربية السعودية
}

Received: Oct. 16,2017

Accepted: Oct. 30,2017

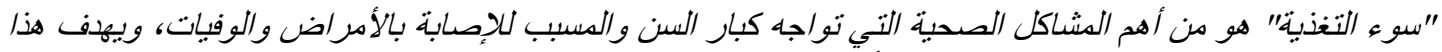

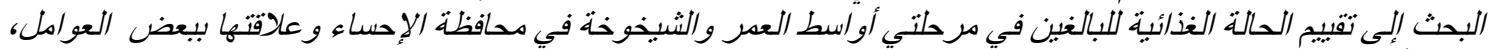

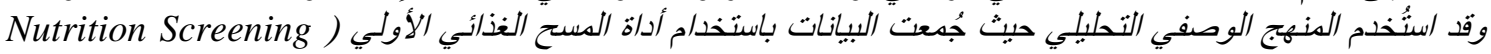
(Initiative -NSI

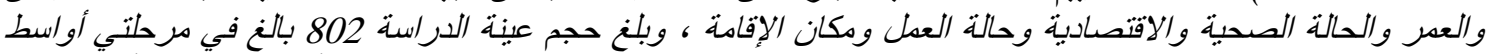

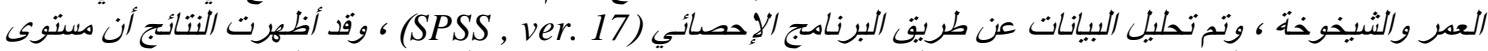

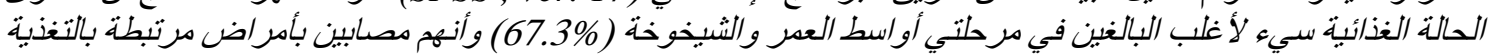

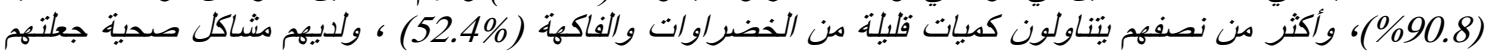

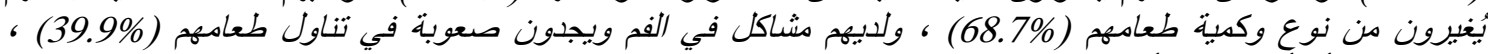

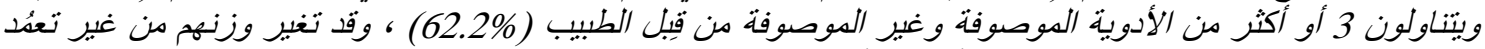

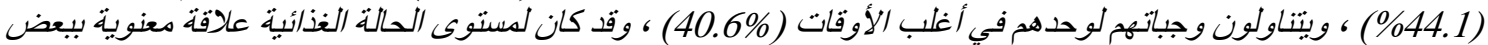

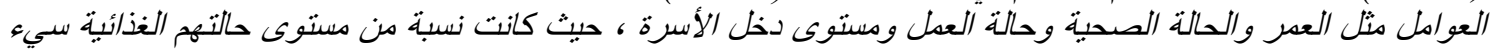

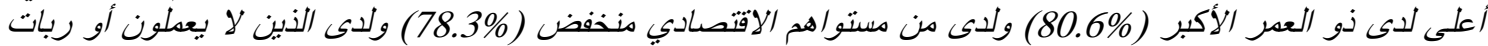

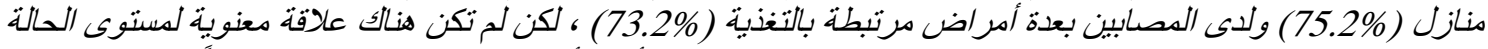

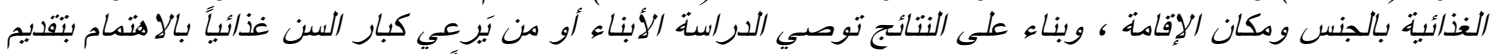

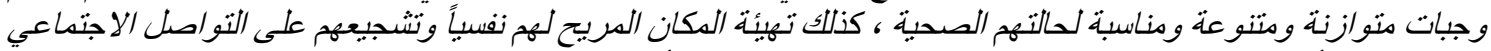

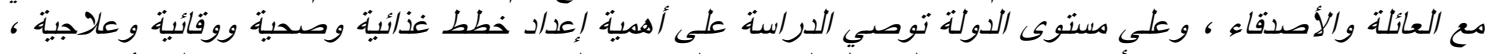

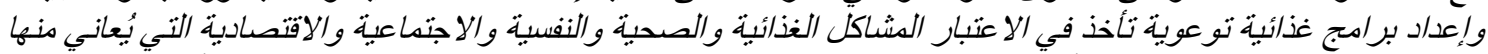
كبار السن ، وتقليم خدمات صحية أولية وتدريب العاملين الصحبين خاصنة المسئولين عن الرعاية الصحية الأولية لكبار السن السين

الكلمات الاسترشادية : أداة المسح الغذائي الأولي ، تقييم الحالة الغذائية في مرحلتي أواسط العدر والشيخوخة ، سوء التغذية،

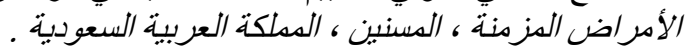

Alibhai et al. 2005 ؛t al. 1998 ؛ أمين وشاهين ، 2005) ، وتتأثر هاتين المرحلتين بالعوامل الوراثية و البيئية (مثل النمط الغذائي والحياتي) وعو امل اقتصادية ونفسية واجتماعية (العزلة والوحدة وفقد أحد الزوجين)

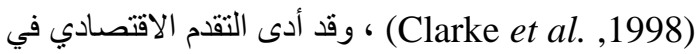
المملكة العربية السعودية في العقود الأخيرة إلى انخفاض الوفيات الناتجة عن الأمراض الوبائية والطفيلية ونقص لفي التغذية ، وزيادة الوفيات الناتجة عن أمراض الرفاهية (الأمراض المزمنة) ، كما أدى تحسن الرعاية الصحية وتوفر الغذاء إلى ارتفاع في متوسط العمر المتوقع ، (المدني ،2005 ؛ المدني ،2005ب) ـ ونواجه كبار السن
المقدمة

قُسمت البالغية من الناحية التغذوية إلى أربع فئات عمريه وهي من العمر 19 - 30 عاماً ومن 31 - 50 عاماً ويمكن جمعهما ليمثلا البالغية المبكرة ، ومن العمر 51 - 70 عاماً وهي فئة أو اسط العمر ثم البالغية المتأخرة (الثيخوخة) وهي الفئة العمرية الأكبر من 70 عاماً

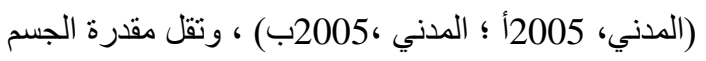

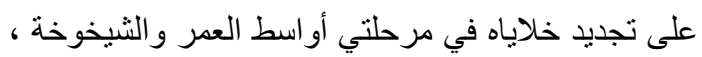
مما يؤدي إلى تغيرات عديدة مثل بطء عملية التمثيل الغذائي وتغير ات فسيولوجية حيث تتخفض القدرة الوظيفية لمعظم أجهزة الجسم وتتدهور الحواس (التذوق والثم و النظر ) وتسقط الأسنان ويصعب المضن و البلع ( Clarke 
2012, et al ) ، وهذه الأدوات متشابه في بعض بنودها

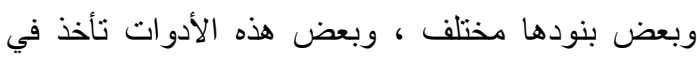
الاعتبار بعض التحاليل المخبرية و القياسات الجسمية لكبار السن ، وفي الدر اسة الحالية تم استخدام أداة السسح الغذائي الأولي كوسيلة لتقييم البالغين في مرحلتي أواسط العرد

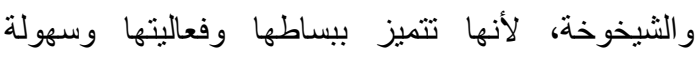
استخدامها وهي اقتصادية (غبر مُكلفِة) ونتائجها مقبولة (2010, Small) وقد بيّنت بعض الدراسات بأن هذه

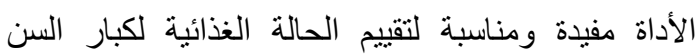

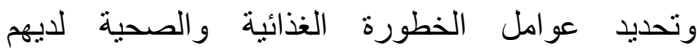
Sherina ؛ Jensen et al. ,2001 ؛ Bonilla ,1995) •(Small 2010 ؛ Sinnett, 2009 ؛ et al. 2004 والبعض اعتبرها أداة تعليمية ونوعوية لأنها تزيد الوعي

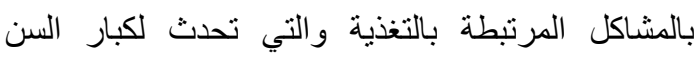
1800 (MacLellan and Van Til,1998) أخصائي وأخصائيات تغذية من 50 و لاية أمريكية عدد من

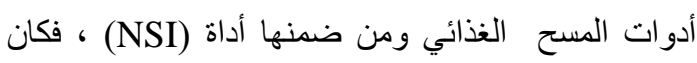
إجابتهم بأنهم يعرفون هذه الأداة (61.2\%) ويستخدمونها

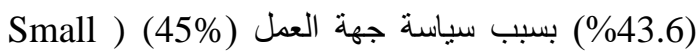
2010,) ، وقد قُيمّت الحالة الغذائية لكبار السن باستخدام

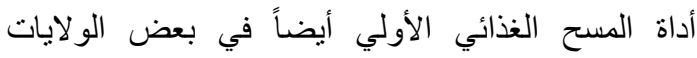

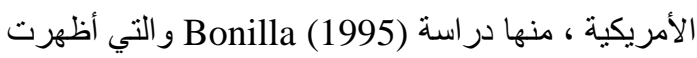
أن الحالة الغذائية كانت سيئة لاى 30.3\% من كبار السن

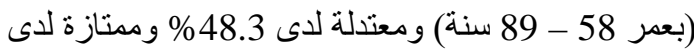

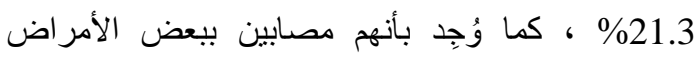
المزمنة مثل السمنة وأمر اض الأوعية الدموية ، دراسة لإنة MacLellan and Van Til (1998) الغذائية كانت سيئة لدى 10\% من كبار السن (بعمر 70

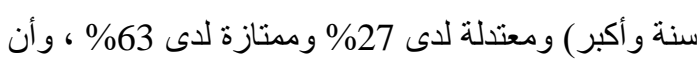

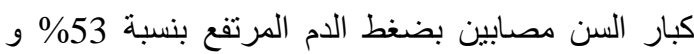
37\% لدى الذين بعمر 70 -79 سنة وبعمر 80 سنة وأكبر

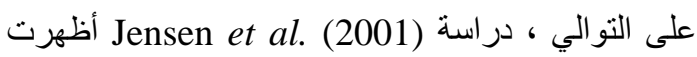
أن الحالة الغذائية لدى كبار السن (بعمر 65 سنة وأكبر)

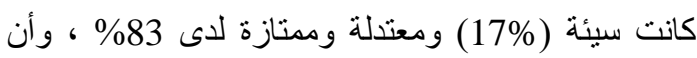
بعض كبار السن مصابين ببعض الأمر اض المزمنة (مثل
عديد من المشاكل الصحية المرتبطة بتغذيتهم منها سوء التغذية و السمنة و أمر اض القلب و الأو عية الدموية وهشاشتة العظام وقصور الأنظمة المناعية (أمين وشاهين ،2005) ، لذا يحتاج كبار السن لحل مشاكلهم إلى تدخلات تأخذ في الأني

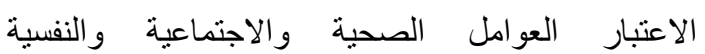

والاقتصادية و الديمو غر افية ( Kimokoti and Hamer 2008,) ، وتوصي الإرشادات الغذائية الأمريكية والإرشادات الغذائية الصحية لدول الخليج العربية كبار السن بالاهتمام بتناول وجبات منوازنة ومتنوعة غنبة الإنية بالخضار والفاكهة وقلبلة الصوديوم والدهون الدشبعة

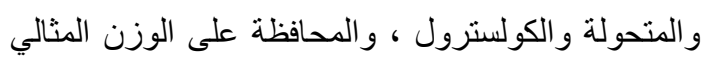

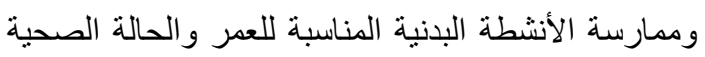

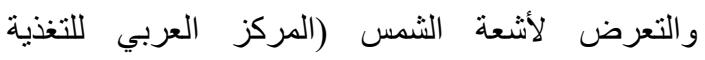

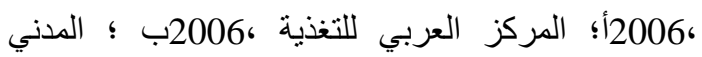

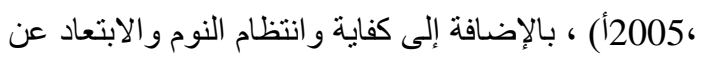

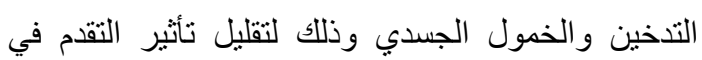

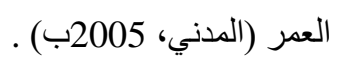

و هناك وسائل و أدوات عديدة لتحديد مستوى الحالة الغذائية للبالغين (الثباب وكبار السن) منها بعض التحاليل المخبرية مثل مسنوى الالبومين في الدم ، ففي حال انخفاضه فهذا مؤشر خطر لحدوث سوء التخذية ( Ritchie Alhamdan ؛ Reuben ,2004 ؛ et al. 1997 2004), ، وتستخدم بعض القياسات الجسمية مثل مؤشر كتلة الجسم ومحيط الخصر وسمك طية الجلد لتحديد مستوى الحالة الغذائية أيضاً (2004, Alhamdan ؛ ؛ Ficklen et al. 2011 ؛ Reddy et al. 2014 2013, (Castro-Costa et al. ) كما تستخدم أدوات

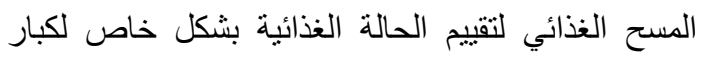
السن مثل أداة المسح الغذائي الأولي (NSI) وأداة التقيبم الغذائي الصغيرة (MNA) وأداة التقييم الغذائي القياسية ولية التئي

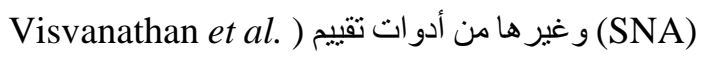
Phillips et ؛ Kruizenga et al. 2005, 2004 Rist ؛ Elsawy and Higgins ,2011 al. 2010 


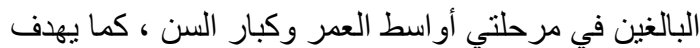

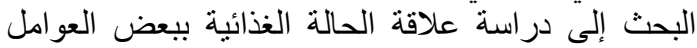

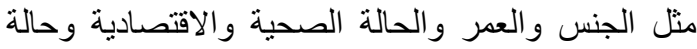

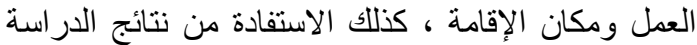

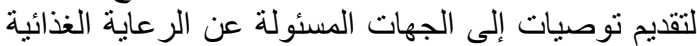

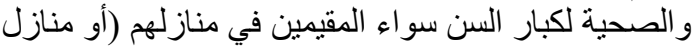
أبنائهم) أو المقيمين في دور رعاية المسنين المنين فيناز

\section{طريقة الاراسة وإجراء|تها} منهج الاراسة النة

تم استخدام المنهج الوصفي التحليلي لملائمته للار اسة.

$$
\text { أدوات الدراسة }
$$

تم جمع بيانات الدراسة باستخدام أداة المسح الغذائي

الأولي (Nutrition Screening Initiative -NSI) كمقياس لتقييم الحالة الغذائية للبالغين في مرحلتي أواسط

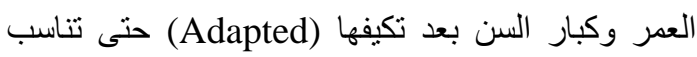
المجتمع السعودي بالإضافة إلى جمع بعض البيانات العامة

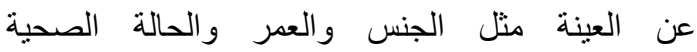
والاقتصادية وحالة العمل ومكان الإقامة لعينة الدراسة ، ولألة

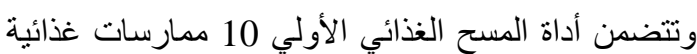
وصحية ، وكل ممارسة يقابلها درجة معينة تُستخدم التقييم إجابة مفردة عينة الدراسة إذا كانت "نعم" (جدول 1) ،

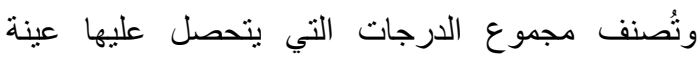
الدراسة إلى 3 مستويات للحالة الغذائية ، الحالة الغذائية ممتازة ومعتدلة وسيئة ، وكلما زادت الدرجات التي لتئي يتحصل عليها مفردة عينة الدراسة فإن حالته الغذائية

$$
\text { اعتُبرت سيئة و العكس صحيح . }
$$

أمراض القلب وداء البول السكري) ، وحدث لهم فقد في أوزانهم ولديهم مشاكل في الأكل وهذا جعلهم يتبعون

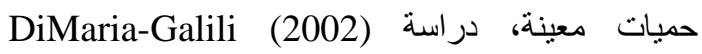
أظهرت أن الحالة الغذائية كانت سيئة لاى 18.7\% من كبار السن (بعمر 65 سنة أو أكبر) ومعتدلة لدى 56\% وممتازة لاى 25.3\%، وأن وضعهم الصحي أدى إلى الى تغير في وزنهم وأستدعى تغير طعامهم كماً ونوعاً Sinnett وتناولهم أدوية أكثر من 3 أنواع ، دراسير (2009) أظهرت أن الحالة الغذائية كانت سيئة لدى 74 الدئ من كبار السن (بمتوسط عمر 75 سنة) لأنهم يمارسون عادات غذائية سيئة ، أما نسبة من حالته الغذائية معتدلة وممتازة فقد بلغت 19\% و 7 \% على التوالي ، وفي

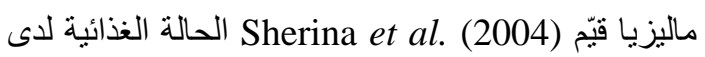
كبار السن (بعمر 60 - 93 سنة) ، فؤجدِ أن نسبة من حالتهم الغذائية سيئة ومعتدلة بلغت 36.3\% و 25.3

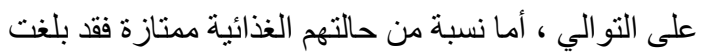

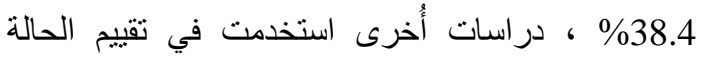

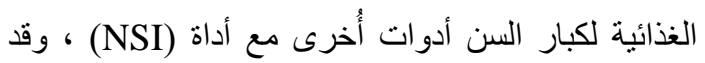
أظهرت أن الحالة الغذائية لبعض كبار السن سيئة لكن بنسب منباينة تبعاً لنوع الأداة المستخدمة للتقيبم Kucukerdonmez ؛ Visvanathan et al. ,2004) . (et al. ,2005 و لأن كبار السن بعتبرون من الفئات الحساسة والأكثر

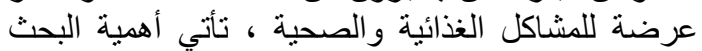

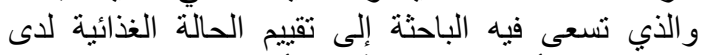

\begin{tabular}{|c|c|}
\hline 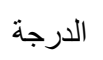 & 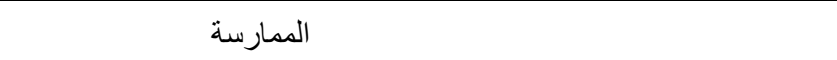 \\
\hline 3 & أتنتاول أقل من وجبتين في اليوم \\
\hline 2 & أتناول كميات قليلة من الخضراوات و الفاكهة \\
\hline 2 & أُكثر من تناول الأغذية الدسمة و الحلويات \\
\hline 1 & أتناول الطعام بمفردي في أغلب الأوقات \\
\hline 4 & ليس دائماً لدي المال الكافي لثراء الطعام الذي احتاجه \\
\hline 2 & ليس دائماً لدي القدرة على طبخ الطعام أو إطعام نفسي \\
\hline 2 & لدي مشاكل في الفم والأسنان تجعلني أجد صعوبة في تناول الطعام \\
\hline 2 & لدي حالة أو مرض جعلني أُغِّرِ من نوع أو كمية الطعام الذي أنتاوله \\
\hline 2 & وزني زاد أو نقص (حو الي 4.5 كيلو) من غير تعُدّ في الستة شهور الماضية \\
\hline
\end{tabular}
جدول (1) : أداة المسح الغذائي الأوليث 


\begin{tabular}{|c|c|}
\hline 1 & أتناول 3 أو أكثر من الأدوية الموصوفة أو غير الموصوفة من قِبل الطبيب \\
\hline 21 & المجموع \\
\hline
\end{tabular}

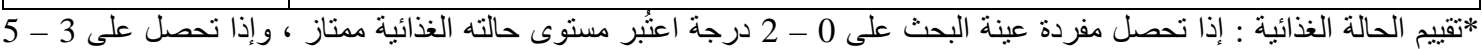

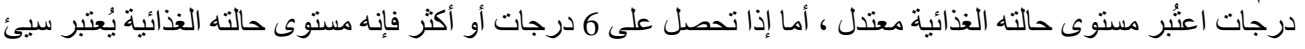

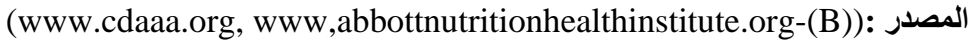

وبلغ عدد النسخ المُستردة (802) وبهذا بلغت نسبة

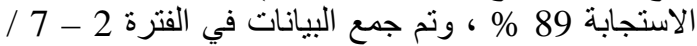

. 2015

\section{التحاليل الإحصائية}

تم تحليل البيانات باستخدام برنامج حزمة البرامج

، الإحصائية للعلوم الاجتماعية ( SPSS , ver. 17

وعرضت النتائج بصورة تكرارات ونسب مئوية

ومتوسطات، وتم استخدام اختبار مربع كاي (كا2) لدر اسة علاقة الحالة الغذائية لأوسط العمر وكبار السن ببعض العو امل مثل الجنس و العمر و الحالة الصحية و الاقتصادية وحالة العمل ومكان الإقامة ، و اعتُرت العلاقة ذات دلالة إحصائية عندما تكون قيمة الاحتمال أقل أو تساوي 0.05 ( أبوسريع ، P (2004) 0.05)

\section{التتائج والمناقشة}

بعد إجراء المعاملات الإحصائية المناسبة ، أسفرت

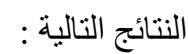

أولاً : بعض المعلومات عن المتغيرات الديموغرافية

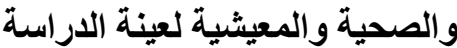

يوضح جدول (2 و 3) بعض المتغيرات الديمو غر افية

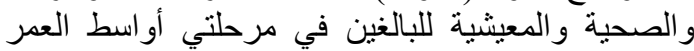

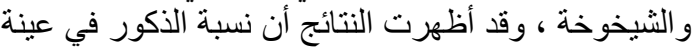

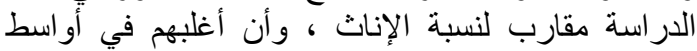

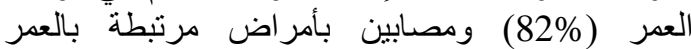
(90.8\%) ، حيث وُجد أن 43.3 \% \% مصابين بانين بأكثر من

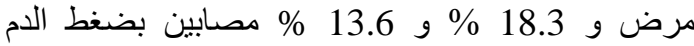
المرتفع وداء البول السكري على التوالي و 18.6 \% و 13.6 مصابين بحموضة ولفة المعدة والسمنة وتصلب الشري الشين

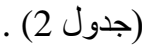

وتتميز أداة المسح الغذائي الأولي (INS) ببساطها وسهولة استخدامها وفعاليتها وهي اقتصادية (غير مُكلفِة) وذات مصداقية ونتائجها مقبولة ، وتكون متوفرة ضمن وله وله النظام الالكتروني في الجهة المسئولة عن تقييم الحالة Small ) الغذائية لكبار السن (في المستشفيات مثلاً) 2010, ؛ 2012, (Skipper et al. ، كما بيّت عدة (2012 در اسات بأن هذه الأداة مفيدة ومناسبة لتقييم الحالة الغذائية وتحديد عوامل الخطورة الغذائية والصحية لكبار السن Sherina ؛ Jensen et al. ,2001 ؛ Bonilla ,1995) Sinnett 2009 ؛ et al. 2004 (www.abbottnutritionhealthinstitute.og-(A)؛

ثبات الأداة المستخدمة لتقييم الحالة الغذائية

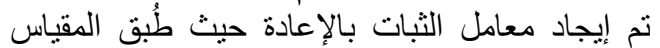

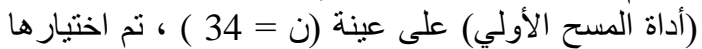

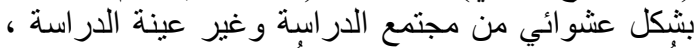

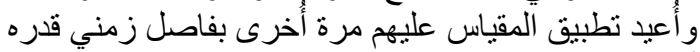

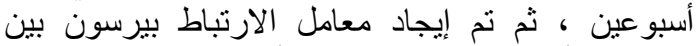

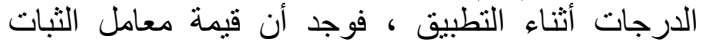

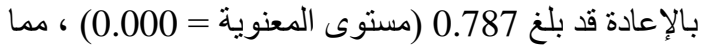

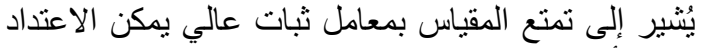

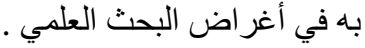

كما تم حساب ثبات المقياس باستخدام معادلة ألفا

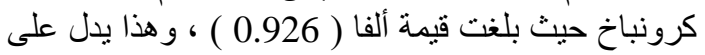
ثبات المقياس . ت كرون

عينة الدراسة تم توزيع عدد 900 نسخة من الاستبيان (متضمن الدانة أداة

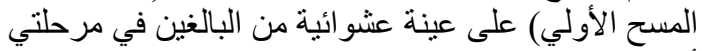

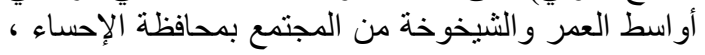

جدول (2) : بعض المتغيرات الديموغرافية والصحية لعينة الدراسة

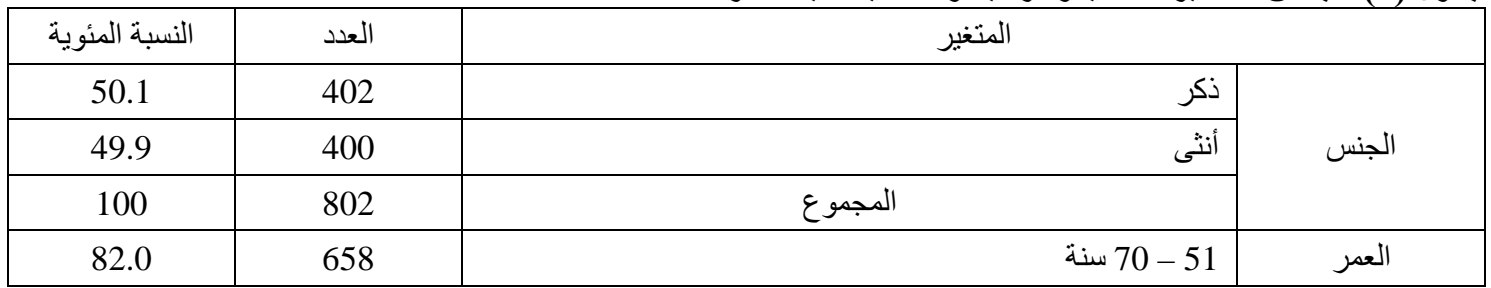


Nutritional evaluation of middle and old age adults

\begin{tabular}{|c|c|c|c|}
\hline 18.0 & 144 & أكبر من 70 سنة & \\
\hline 100 & 802 & المجموع & \\
\hline 9.2 & 74 & غير مصاب بأمر اض مرتبطة بالتغذية & \multirow{8}{*}{ الحالة الصحية } \\
\hline 18.3 & 147 & ضغط الدم المرتفع & \\
\hline 13.6 & 109 & داء البول السكري & \\
\hline 7.9 & 63 & حموضة المعدة & \\
\hline 6.0 & 48 & 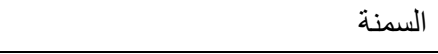 & \\
\hline 1.7 & 14 & تصلب الشر ايين & \\
\hline 43.3 & 347 & أكثر من مرض أو أمر اض أُخرى & \\
\hline 100 & 802 & المجموع & \\
\hline
\end{tabular}

\begin{tabular}{|c|c|c|c|}
\hline$\%$ & العدد & المتغير & \\
\hline 15.2 & 122 & موظف//ة & \multirow{4}{*}{ حالة العمل } \\
\hline 65.7 & 527 & متقاعد/ة & \\
\hline *19.1 & 153 & لا يعمل - ربة منزل & \\
\hline 100 & 802 & المجموع & \\
\hline 62.8 & 504 & المدينة & \\
\hline 37.2 & 298 & القرية & مكان الإقامة \\
\hline 100 & 802 & المجموع & \\
\hline 26.9 & 216 & أقل من 3000 ربال & \\
\hline 29.3 & 235 & 3000 -6000 ربال & \\
\hline 16.0 & 128 & أعلى من 6000 -10000 ربال & الأسرة الشهرى دخل \\
\hline 27.8 & 223 & أعلى من 10000 ربال & \\
\hline 100 & 802 & المجموع & \\
\hline
\end{tabular}

؛ Kimokoti and Hamer ,2008 ؛ et al. ,2005

Reddy et al. ؛ Castro-Costa et al. ,2013

. (AbdelRahman et al. ,2014 2014

أظهرت النتائج في جدول (3) أن أغلب عينة الدراسة (62.78)

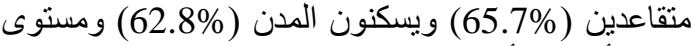

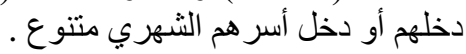

ثنانياً : الحالة الغذائية للبالغين في مرحلتي أواسط

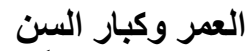

1-الأغذية الأقّل استهلاكاً لاى البالغين في مرحلتي أوسط

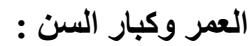

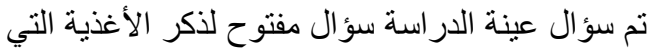

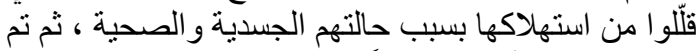

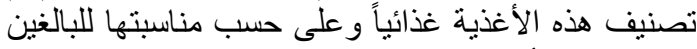

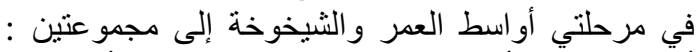
أغذية مناسبة وأغذية غير مناسبة ، المجموعة الأولى مثل
النتائج في الجدول (2) تُشير أنه مع التقام في العمر

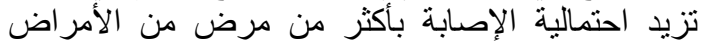

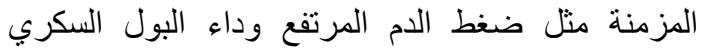

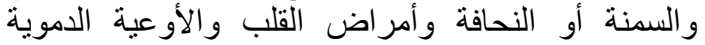

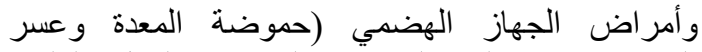

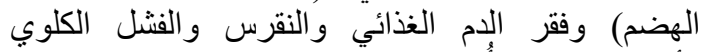

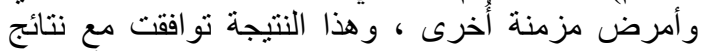

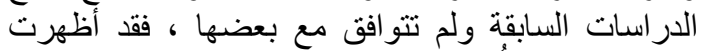

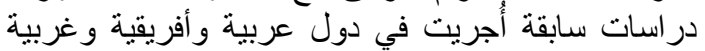
و لاتينية وأسيوية انتثار العديد من الأمر اض اض المزمنة بينة بين

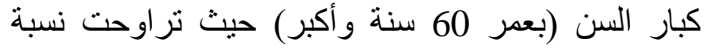

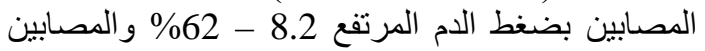

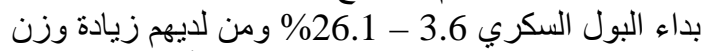
وسمنة 6.6 - 52.8\% بالإضافة إلى أمراض مزمنة أخرى (1993, Posner et al ؛ MacLellan and Van Til ؛ Jensen et al. 1997 Kucukerdonmez ؛ Alhamdan 2004, 1998 
وقد يكون السبب فقد الأسنان وصعوبة المضغ والبلع أو قلة شهيتهم للأكل (بسبب فقدهم لبعض الحواس مثل الثم) أو بسبب حالتهم الصحية أو بسبب مشاكل في الجهاز الهضمي (مثلاً حموضة المعدة) ، وُجِد أيضاً أن 23.9\% يُكثرون من تناول الأغذية الدسمة و الحلويات ، مما قد يزيد

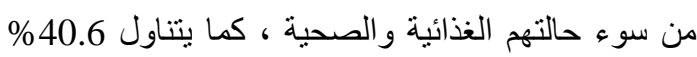
من عينة الدراسة طعامهم في الغالب بمفردهم ، وقد يكون السبب موت أحد الزوجين أو استقلالية الأبناء (بسبب زواجهم) ، كما يعاني قليل من عينة الدر اسة من عدم توفر مال كافٍ لثراء طعامهم (9.7\%) ، لكن أغلبهم ينوفر

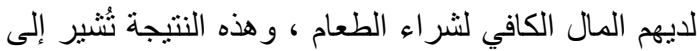
التزام الأبناء إلى الاعتناء بالوالدين بتوفير احتياجاتهم

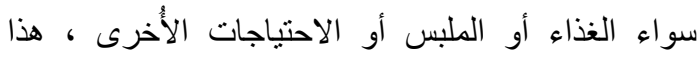
بالإضافة إلى أن بعض كبار السن من الذين خدموا الدولة

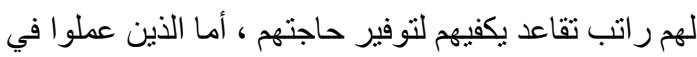
وظائف حرة (غير حكومية) وليس لهم راتب تقاعد فإن الدولة تدعمهم مادياً في حال استقلالية أبنائهم ، كما أن الدولة والمؤسسات الخيرية و القطاع الخاص يوفرون دور للمسنين لرعايتهم غذائباً وصحياً في حال عدم وجود أبناء قادرين على رعاية ابائهم (المدني ،2005ب) .

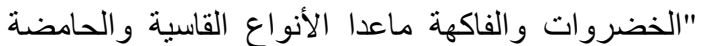

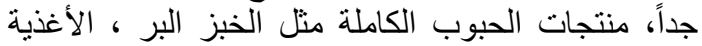

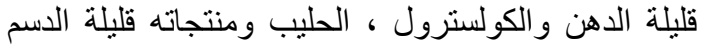

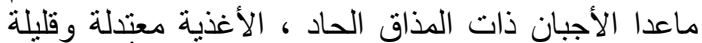

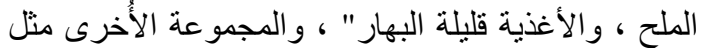

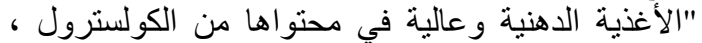

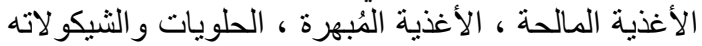

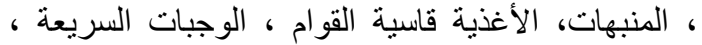

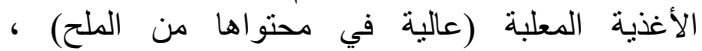

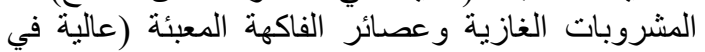

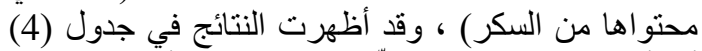

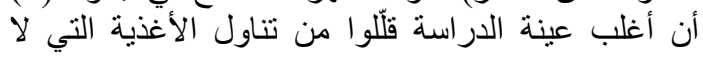

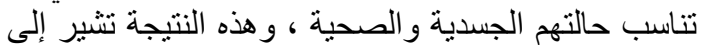
اهتمام كبار عينة الدارسة إلى تجنبهه تناول الأغذية التية التئي

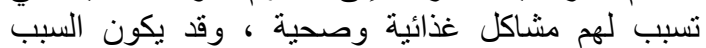

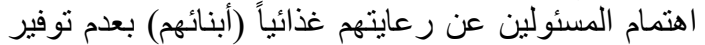

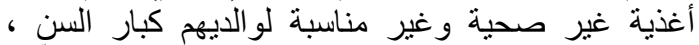

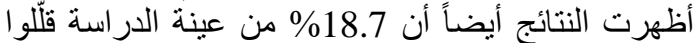

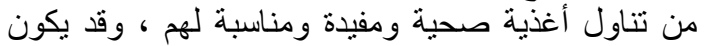
السبب عدم تفضيلهم لبعض هذه الأغذية .

2-تقييم الحالة الغذائية للبالغين في مرحلتي أواسط العمر

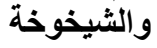

يوضح جدولي (5 و 6) بعض بالئل الممارسات الصحية

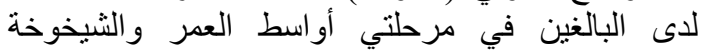
ومستوى الحالة ألغذائية لهم ، ولئ وقد أظهرت النتائج في

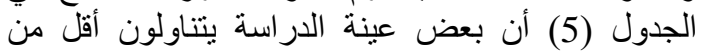
وجبتين في اليوم (17.3\%) وهذا لا يلبي احتياجاتهم الغذائية . - الغين

أظهرت النتائج في الجدول (5) أن أعلى من نصف

العينة يتناولون كمبات قليلة من الخضراوات والفاكهة ،

جدول (4) : الأغذية الأقل استهلاكاً لاى البالغين في مرحلتي أواسط العمر و الثيخوخة

\begin{tabular}{|c|c|c|}
\hline النسبة المئوية & 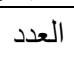 & الأغذية الأقل استهلاكاً لدى عينة الدراسة \\
\hline 18.7 & 150 & أغذية مناسبة \\
\hline 61.2 & 491 & أغذية غير مناسبة \\
\hline 20.1 & 161 & الاثثين \\
\hline 100 & 802 & المجموع \\
\hline
\end{tabular}

\begin{tabular}{|c|c|c|c|c|c|c|c|c|}
\hline \multirow{2}{*}{ 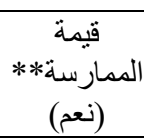 } & \multirow{2}{*}{ الممارسة } & \multicolumn{2}{|c|}{ 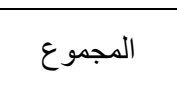 } & \multicolumn{2}{|c|}{$y$} & \multicolumn{2}{|c|}{ نعم } & \multirow{2}{*}{ الممارسة الغذائية و الصحية } \\
\hline & & $\%$ & العدد & $\%$ & العدد & $\%$ & العدد & \\
\hline 3 & 0.52 & 100 & 802 & 82.7 & 663 & 17.3 & 139 & تناول أقل من وجبتين في اليوم \\
\hline 2 & 1.05 & 100 & 802 & 47.6 & 382 & 52.4 & 420 & تالفاكهة كميات قليلة من الخضر اوات \\
\hline 2 & 0.48 & 100 & 802 & 76.1 & 610 & 23.9 & 192 & كثر من تتاول الأغذية الدسمة و الحلويات \\
\hline 1 & 0.41 & 100 & 802 & 59.4 & 476 & 40.6 & 326 & تناول الطعام بدفردي في أغلب الأوقات \\
\hline
\end{tabular}


Nutritional evaluation of middle and old age adults.

\begin{tabular}{|c|c|c|c|c|c|c|c|c|}
\hline 4 & 0.39 & 100 & 802 & 90.3 & 724 & 9.7 & 78 & لليس دائماً لدي المال الكافي لشر اء الطعام \\
\hline 2 & 0.75 & 100 & 802 & 62.3 & 500 & 37.7 & 302 & الطعام دائماً لإي القعام نفسي على شر اء وطبخ \\
\hline 2 & 0.80 & 100 & 802 & 60.1 & 482 & 39.9 & 320 & لدية مشاكل في الفم و الأسنان تجعلني أجد \\
\hline 2 & 1.38 & 100 & 802 & 31.3 & 251 & 68.7 & 551 & 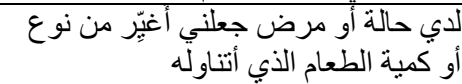 \\
\hline 2 & 0.88 & 100 & 802 & 55.9 & 448 & 44.1 & 354 & وزير تعمُد في أو نقتة شهور (حوالي 4.5 كيلو) من \\
\hline 1 & 0.62 & 100 & 802 & 37.8 & 303 & 62.2 & 499 & 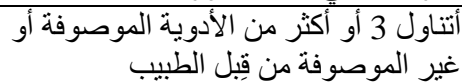 \\
\hline
\end{tabular}

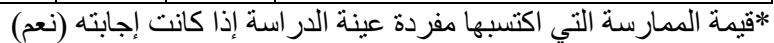

*قيمة الممارسة المرجعية للإجابة (نعم)

\begin{tabular}{|c|c|c|}
\hline \multicolumn{3}{|c|}{ جذول (6) : قيمة ومستوى الحالة الغذائية لاى البالغين في مرحلتي أواسط العمر والثيخوخة } \\
\hline النسبة المئوية & العدد & مستوى الحالة الغذائية لعينة الدراسة \\
\hline 67.3 & 540 & حالة غذائية سيئة \\
\hline 22.0 & 176 & حالة غذائية معتدلة \\
\hline 10.7 & 86 & حالة غذائبة ممتازة \\
\hline 100 & 802 & 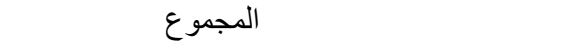 \\
\hline & 7.27 & قيمة الحالة الغذائية (المتو \\
\hline
\end{tabular}

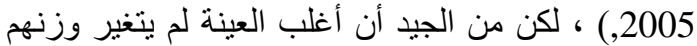

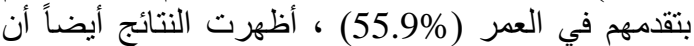

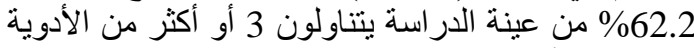

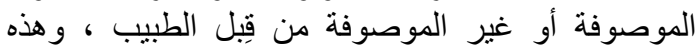

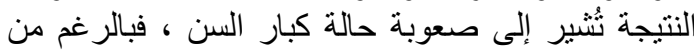

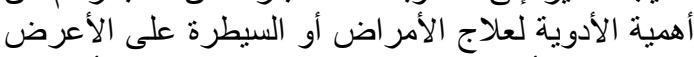

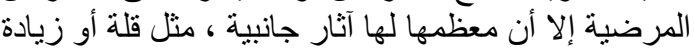

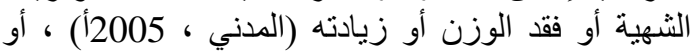

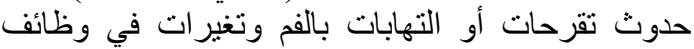

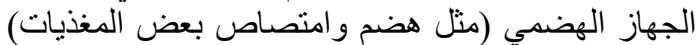

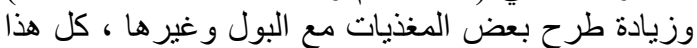

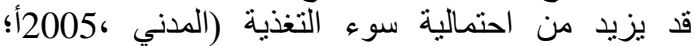

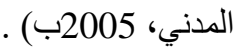

أظهرت النتائج في الجدول (6) أن مستوى الحالة الغئل

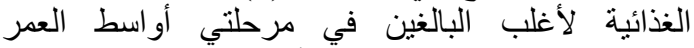
و الثيخوخة سيئ (67.3\%) ، وأن مستوى الحالة الغذائية لخُمس العينة معتدل (22.0\%) ، أما كبار السن الذئن الذين مستوى حالتهم الغذائية ممتاز فقد كانت نسبتهم قليلة النين

. (\%10.7)

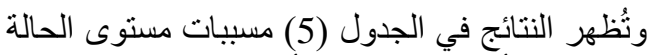
الغذائية السيئة لأظلب البالغين في أو اسط العمر و والثيخوخة

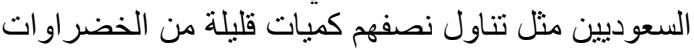

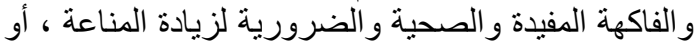

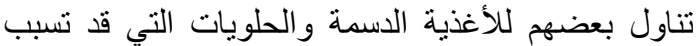
بعض الأمر اض و التي بدور ها تؤثر على على حالتهم الغذائية ، كما أن تناول 40.6\% من كبار السن طعامهم في الغالب

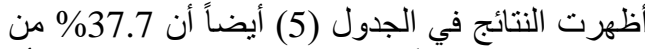

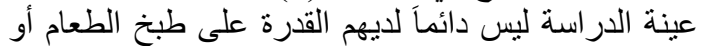

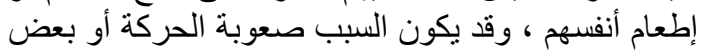

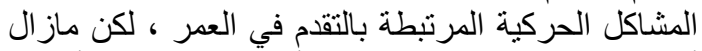

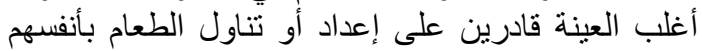

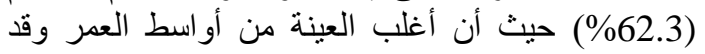

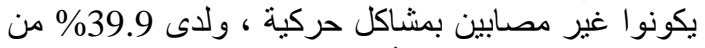

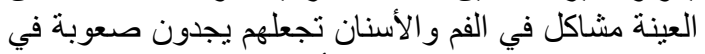

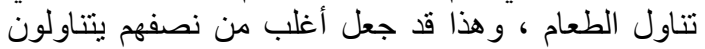

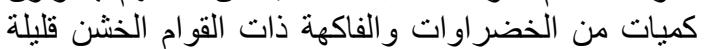

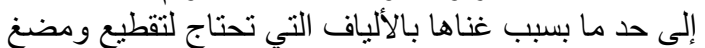

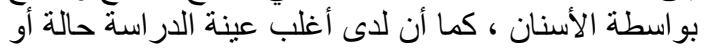

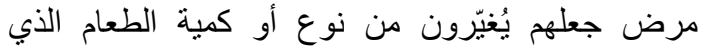

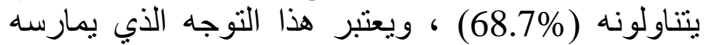

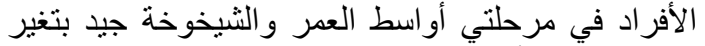

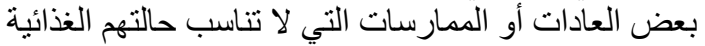

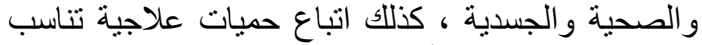

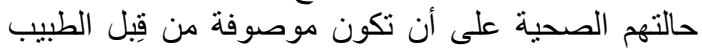

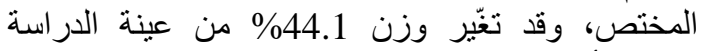
بالزيادة أو النقص من غير تعندمد في الستة شهور الماضية

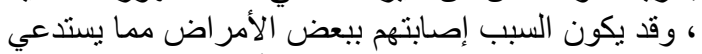
تقليلهم كمية المتناول من الطعام أو قد بؤثر لأثر مرضهر

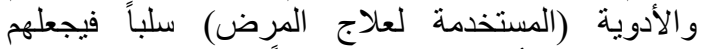
يتناولون كمية أكبر من الطعام مؤدياً ذللك لزيادة الوناد الوزن لكن

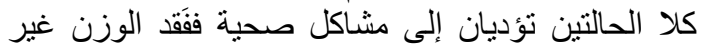
المُتعدد له آثار خطيرة على القيان القدرة الوظيفية ونو عية الحياة

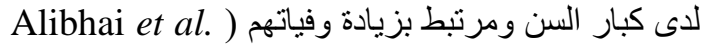


الماضية ما بين 8 - 44.6\% ، أما نسبة الذين يتناولون 3 أو أكثر من الأدوية الموصوفة أو غبر الموصوفة من من قِبِل الطبيب فقد تراوحت ما بين 21.7 - 80sner et ) 8

؛ Cobiac and Syrette 1995 ؛ al. 1993

؛ Jensen et al. ,1997 ؛ Bonilla ,1995

Quandt and ؛ MacLellan and Van Til,1998

؛ Keller and Hedely 2002 ؛ Chao ,2000

Patterson et al. ,2002 \ DiMaria-Galili ,2002

Sherina et al. ؛ Sharkey and Haines, 2002 ؛

؛ Salehi et al. 2010 ؛ Sinnett 2009 2004

. (Wunderlich et al. ,2012

أجريت بعض الدر اسات اعتُمِدَ فيها على تصميم بعض إنَ

بر امج التقيف الغذائي والصحي لكبار السن ، بهدف زيادة

المعرفة الغذائية والصحية وكوسيلة لتحسين الحالة الغذائية

والصحية لهم ، منها دراسة (2007) . Wellman et al.

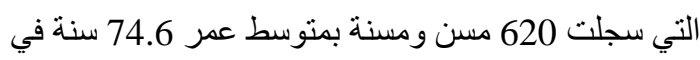

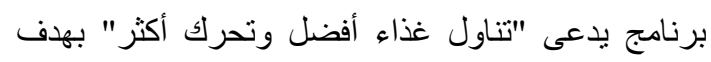
تحسين وجبات المسنين الأمريكيين وزيادة نشاطهم البدني

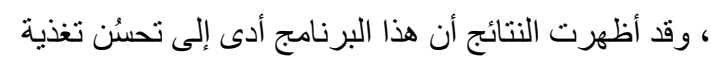

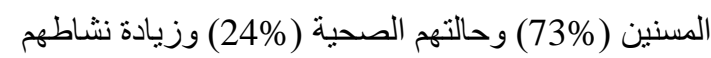

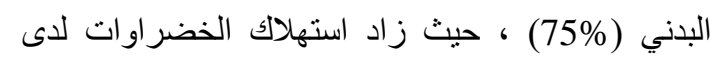

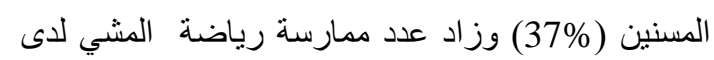

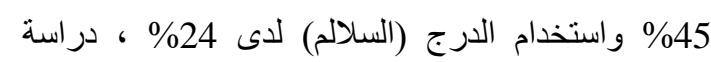
أخرى لـ Southgate et al. S2010) ، وفيها انضم

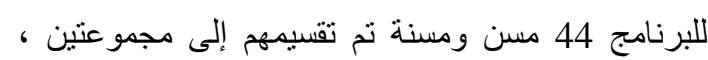
الأولى أرسل لهم بالبريد كتيبات تثقيفية غذائية تحفز هم على تغيير سلوكياتهم الغذائية السيئة بالإضافة إلى رسائل تحثهم على زيادة الاستهلاك اليومي من الخضراوات الفيكاتل

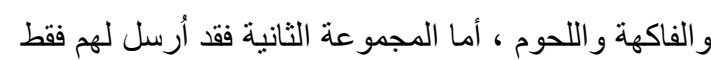

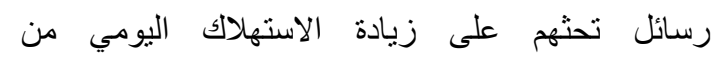

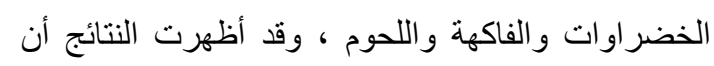

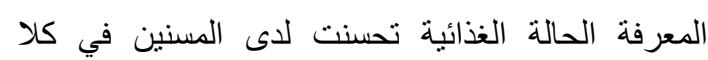

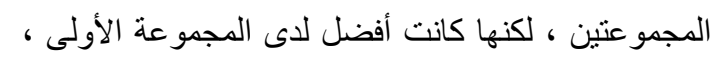
كما صمم (2013) Kimura et al. برنامج تدخل مجتمعي بهدف تحسين عادات التغذية وتعزيز النشاط

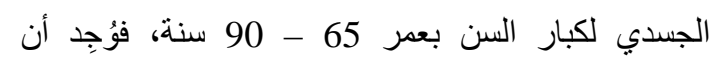
البرنامج الاجتماعي الصحي قد أدى إلى تحسين عادات

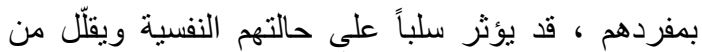

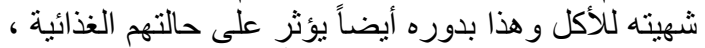

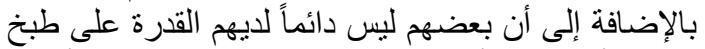

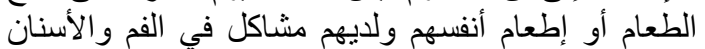

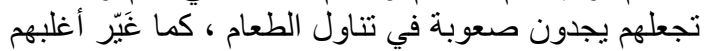

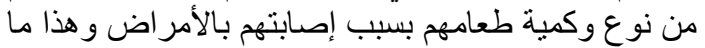

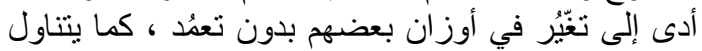

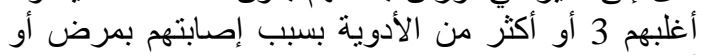
أكثر مرتبط بالتغذية (90.8\%) (جدول 2) من الادوية )

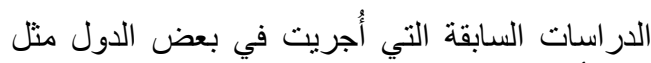

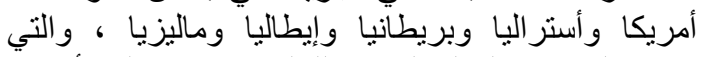
هدفت إلى تقييم الحالة الغذائية للبالغين في مرحلتي أو أسطا

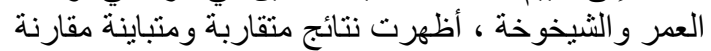

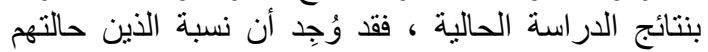

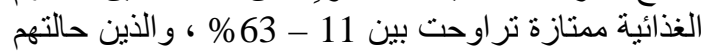

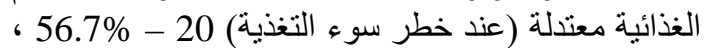

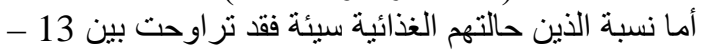
Cobiac and ؛ Posner et al. ,1993) \%65 MacLellan ؛ Bonilla ,1995 S Syrette,1995 Keller and Hedely ,2002 ؛ and Van Til,1998 Patterson et al. ؛ DiMaria-Galili ,2002 ؛ ؛ Sherina et al. (2004 ؛ 2002 Sinnett, 2009 ؛ Kucukerdonmez et al. 2005 . (Dorner et al. 2014 ؛ Donini et al. ,2013

كما أظهرت الدراسات السابقة أن تقدم البالغين في

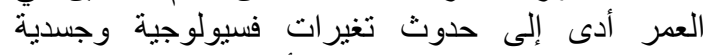

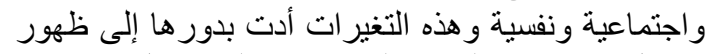

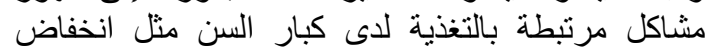

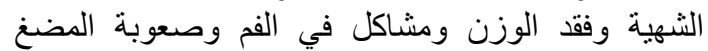

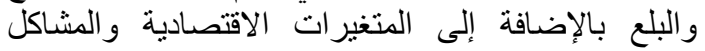

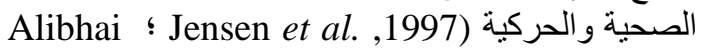
؛ Kimokoti and Hamer ,2008 et al. ,2005 AbdelRahman et al. ؛ Donini et al. 2013

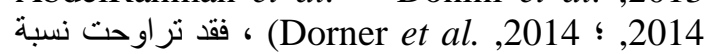

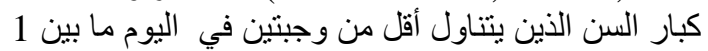

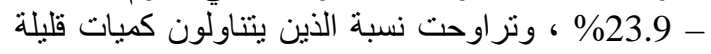

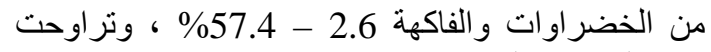

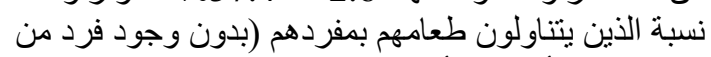

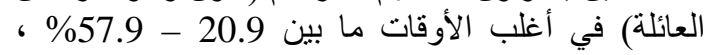

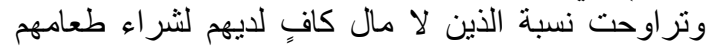

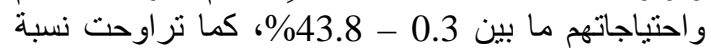
الذين ليس دائماً لديهم القدرة الجسدية على شراء ألماء وطهي

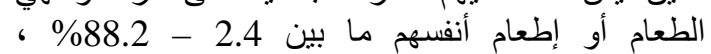

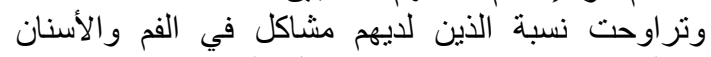

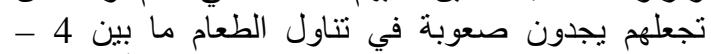

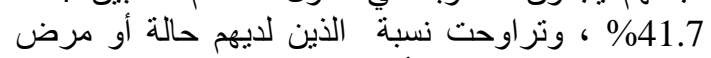

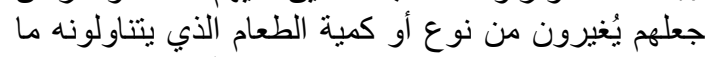

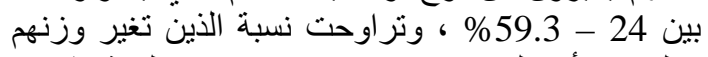
(بالنقص أو الزيادة) من غير تعُدّ في الستة شهور 
النتائج في الجدول (7) تُشير إلى أن لدى ذوي مستوى

الحالة الغذائية الممتاز اهتمام بتعديل بعض ممارساتهم

الغذائية السيئة ، من خلال تقليل تناول الأغذية التي لا

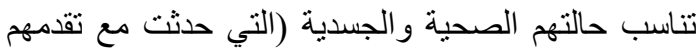
في العمر) ، وقد يكون سبب ذلك اتباعهم لنصائح وارشادات أطبائهم بإجراء تعديلات لبعض ممارساتهم الغذائية .

أظهرت النتائج في الجدول (8) أن علاقة الحالة الغذائية بالعمر كانت معنوية (P = 0.000) فأغلب من حالتهم الغذائية سيئة هم من بعمر 70 سنة أو أكثر مقارنة بمن عمر هم 51 - 70 سنة (80.6\% و 64.6\% بعر على التوالي) وبالعكس فقد كانت نسبة ذوي حالة الغذائية

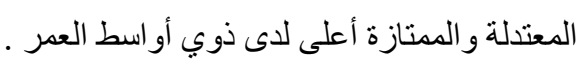
نتائج الدراسة الحالية نوافقت مع الدراسات السابقة

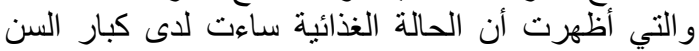

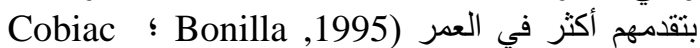
؛ Sherina et al. 2004 ؛ and Syrette, 1995 Sinnett (Buffa et al. 2010 ، ما عدا دراسة (200) (2009) التي أظهرت أن الحالة الغذائية تحسنت مع التقاد

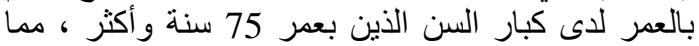

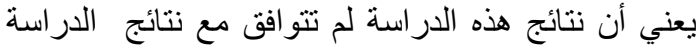

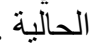

التغذية وعزز النشاط الجسدي للى كبار السن ، أما فقد صمتا برنامج طهي Chung and Chung (2014) وفيه تم إعداد وصفات غذائية مجانية ، بهدف تحفيز شهية كبار السن على الأكل وتحسين حالتهم الغذائية ، وأنضم اللبرنامج 60 مسن ومسنة من هونغ كونغ بعر 59 -95 سنة ، وقد أظهرت النتائج بعد نهاية البرنامج (3 أسابيع)

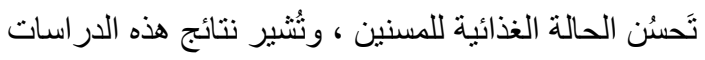

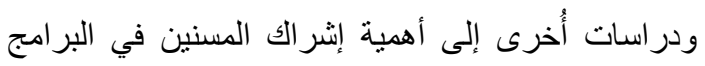
المجتمعية الفعالة لتحسين سلوكياتهم الغذائية والصحية و الحياتية (2010, Kamp ؛ Bernstein and Munoz Keller et al. ؛ Abbott et al. 2013, 2012

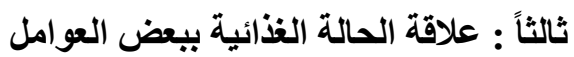

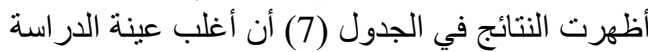

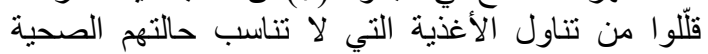

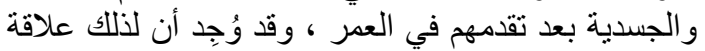
معنوية بالحالة الغذائية (P قلّل من تناول الأغذية غير المناسبة أعلى لدى ذلى ذوي

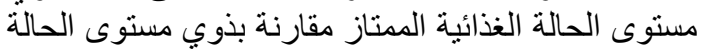

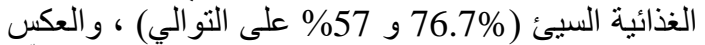
بالنسبة لتقليل الأغذية المناسبة (المفيدة والصحية) فقد قلّل ذو مستوى الحالة الغذائية السيئ منها بنسبة أعلى مقارنة بذوي مستوى الحالة الغذائية المثتاز (20.2\% و 14 الغئ على التو الي) .

جدول (7) : علاقة مستوى الحالة الذذائية بالأغذية الأقل استهلاكاً لاى عينة الدراسة

\begin{tabular}{|c|c|c|c|c|c|c|c|c|}
\hline \multicolumn{2}{|c|}{ المجموع } & \multicolumn{2}{|c|}{ الاثثين } & \multicolumn{2}{|c|}{ أغذية غير مناسبة } & \multicolumn{2}{|c|}{ أغذية مناسبة } & \multirow{2}{*}{ مستوى الحالة الغذائية لعينة } \\
\hline$\%$ & العدد & $\%$ & العدد & $\%$ & العدد & $\%$ & العدد & \\
\hline 100 & 540 & 22.8 & 123 & 57.0 & 308 & 20.2 & 109 & حالة غذائية سيئة \\
\hline 100 & 176 & 17.0 & 30 & 66.5 & 117 & 16.5 & 29 & حالة غذائية معتدلة \\
\hline 100 & 86 & 9.3 & 8 & 76.7 & 66 & 14.0 & 12 & حالة غذائية ممتازة \\
\hline 100 & 802 & 20.1 & 161 & 61.2 & 491 & 18.7 & 150 & المجموع \\
\hline
\end{tabular}

جذول (8) : علاقة مستوى الحالة الغذائية بعمر عينة الدراسة

\begin{tabular}{|c|c|c|c|c|c|c|}
\hline \multicolumn{2}{|c|}{ المجموع } & \multicolumn{2}{|c|}{ أكبر من 70 سنة } & \multicolumn{2}{|c|}{51 - 70 سنة } & \multirow{2}{*}{ مستوى الحالة الغذائية لعينة } \\
\hline$\%$ & العدد & $\%$ & العدد & $\%$ & العدد & \\
\hline 67.3 & 540 & 80.6 & 116 & 64.4 & 424 & حالة غذائية سيئة \\
\hline
\end{tabular}




\begin{tabular}{|c|c|c|c|c|c|c|}
\hline 21.9 & 176 & 17.4 & 25 & 23.0 & 151 & حالة غذائية معتدلة \\
\hline 10.7 & 86 & 2.0 & 3 & 12.6 & 83 & حالة غذائية ممتازة \\
\hline 100 & 802 & 100 & 144 & 100 & 658 & المجموع \\
\hline
\end{tabular}

0.000) ، حيث وُجِد أن نسبة من حالتهم الغذائية سيئة هم

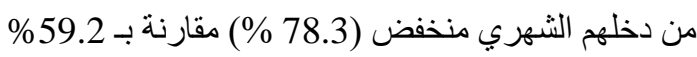

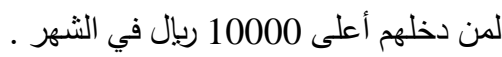

نتائج الدراسة الحالية توافقت مع الدراسات السابقة و التي أظهرت أن أغلب من حالتهم الغذائية سيئة كانوا من لن النه ذوي الدخل المنخفض (1995, Bonilla ؛ Jensen et al.1997) وأن الحالة الغذائية كانت أفضل لدى ذوي الدخل المرتفع (2004, .Sherina et al) . أظهرت النتائج أن علاقة الحالة الغذائية بالحالة الصحية كانت معنوية (P = 0.000) ، فقد وُجدِ أن نسبة

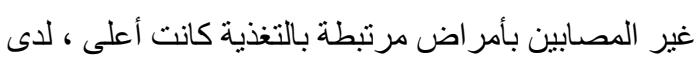
ذوي الحالة الغذائية المتازة مقارنة بذوي الحالة الغذائية السيئة (40.5\% و 35.2\% على التو الي) ، كما أن نسبة

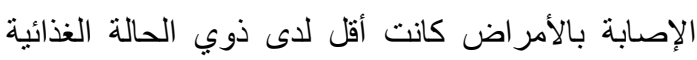
الممتاز مقارنة بذوي الحالة الغذائية المعتدلة و السيئة ، وُجِد الإند أيضاً أن 73.2\% من ذوي الحالة الغذائية السيئة مصابين

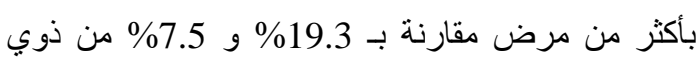

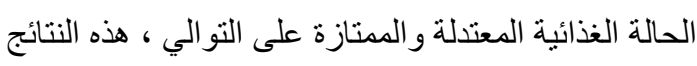

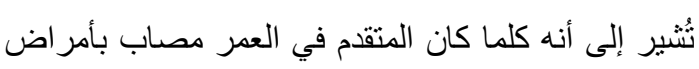

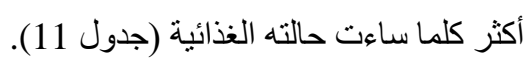

أظهرت النتائج في الجدول (9) أن علاقة الحالة الغذائية بحالة العمل كانت معنوية (P = 0.000) حيث وُجد أن أعلى نسبة حالة غذائية سيئة كانت لدى من لا لانة

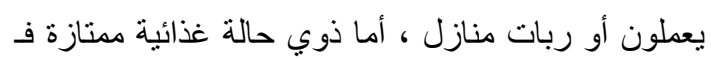
16.4\% منهم موظفين أو موظفات و هي نسبة أعلى مقارنة بالمتقاعدين والذين لا يعملون وربات البيوت (10.3 و و 7.8\% على التو الي ) ، وقد يكون السبب أن الموظفين أقل

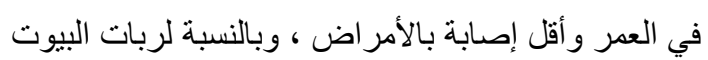
فقد يكون انتشار سوء التغذية بينهن سببه ممارساتهن

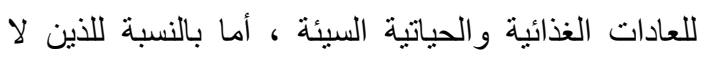
يعملون فقد يكون انتشار سوء التغذية بينهم سببه حالته

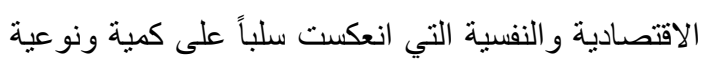

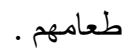
بعض نتائج الدراسة الحالية تو افقت لحد ما مع نتائج دراسة (2004) Sherina et al ، والتي أظهرت بأن الحالة الغذائية للموظفين أفضل مقارنة بالمتقاعدين (الحالة

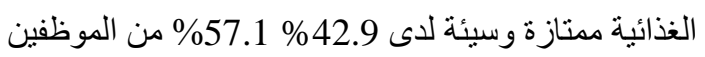
مقارنة بـ 37.9\% و 62.1\% لاى المتقاعدين على وسينه التو الي). أظهرت النتائج في الجدول (10) أن علاقة الحالة

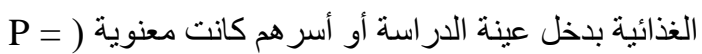
جدول (9) : علاقة مستوى الحالة الغذائية بحالة العمل لاى عينة عينة الداراسة

\begin{tabular}{|c|c|c|c|c|c|c|c|c|}
\hline \multicolumn{2}{|c|}{ المجموع } & \multicolumn{2}{|c|}{ لا يعمل-ربة منزل } & \multicolumn{2}{|c|}{ متقاعد/_ة } & \multicolumn{2}{|c|}{ موظف/_ة } & \multirow{2}{*}{ مستوى الحالة الغذائية لعينة } \\
\hline$\%$ & العدد & $\%$ & العدد & $\%$ & العدد & $\%$ & العدد & \\
\hline 67.3 & 540 & 75.2 & 115 & 69.6 & 367 & 47.5 & 58 & حالة غذائية سيئة \\
\hline 22.0 & 176 & 17.0 & 26 & 20.1 & 106 & 36.1 & 44 & حالة غذائية معتدلة \\
\hline 10.7 & 86 & 7.8 & 12 & 10.3 & 54 & 16.4 & 20 & حالة غذائية ممتازة \\
\hline 100 & 802 & 100 & 153 & 100 & 527 & 100 & 122 & المجموع \\
\hline
\end{tabular}

جدول (10) : علاقة مستوى الحالة الغذائية بلخل عينة الدراسة أو أسرهم 
Nutritional evaluation of middle and old age adults

\begin{tabular}{|c|c|c|c|c|c|c|c|c|}
\hline \multicolumn{2}{|c|}{ المجموع } & \multicolumn{2}{|c|}{ حالة غذائية ممتازة } & \multicolumn{2}{|c|}{ حالة غذائية معتدلة } & \multicolumn{2}{|c|}{ حالة غذائية سيئة } & \multirow{2}{*}{ مستوى الدخل الثشهري لعينة } \\
\hline$\%$ & العدد & $\%$ & 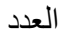 & $\%$ & 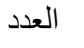 & $\%$ & 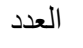 & \\
\hline 100 & 216 & 6.0 & 13 & 15.7 & 34 & 78.3 & 169 & أقل من 3000 ربال \\
\hline 100 & 235 & 8.0 & 19 & 22.6 & 53 & 69.4 & 163 & 3000 -6000 ربال \\
\hline 100 & 128 & 14.0 & 18 & 26.6 & 34 & 59.4 & 76 & أعلى من 6000-10000 ربال \\
\hline 100 & 223 & 16.1 & 36 & 24.7 & 55 & 59.2 & 132 & أعلى من 10000 ربال \\
\hline 100 & 802 & 10.7 & 86 & 22.0 & 176 & 67.3 & 540 & المجموع \\
\hline
\end{tabular}

جدول (11) : علاقة مستوى الحالة الغذائية بالحالة الصحية لعينة الدراسة

\begin{tabular}{|c|c|c|c|c|c|c|c|c|}
\hline \multicolumn{2}{|c|}{ المجموع } & \multicolumn{2}{|c|}{ حالة غذائية ممنازة } & \multicolumn{2}{|c|}{ حالة غذائية معتدلة } & \multicolumn{2}{|c|}{ حالة غذائية سيئة } & \multirow{2}{*}{ الحالة الصحية لعينة الدر اسة } \\
\hline$\%$ & 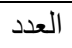 & $\%$ & 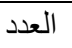 & $\%$ & العدد & $\%$ & 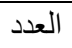 & \\
\hline 100 & 74 & 40.5 & 30 & 24.3 & 18 & 35.2 & 26 & بالتغذية مصاب بأمر اض مرتبطة \\
\hline 100 & 147 & 5.4 & 8 & 27.2 & 40 & 67.4 & 99 & ضغط الدم المرتفع \\
\hline 100 & 109 & 3.7 & 4 & 23.8 & 26 & 72.5 & 79 & داء البول السكري \\
\hline 100 & 63 & 14.3 & 9 & 22.2 & 14 & 63.5 & 40 & حموضة المعدة \\
\hline 100 & 48 & 14.6 & 7 & 18.7 & 9 & 66.7 & 22 & 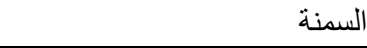 \\
\hline 100 & 14 & 14.3 & 2 & 14.3 & 2 & 71.4 & 10 & تصلب الثر ايين \\
\hline 100 & 347 & 7.5 & 26 & 19.3 & 67 & 73.2 & 254 & أكثر من مرض أو أمر اض أُخرى \\
\hline 100 & 802 & 10.7 & 86 & 22.0 & 176 & 67.3 & 540 & المجموع \\
\hline
\end{tabular}

مرحلتي أواسط العمر وكبار السن ، كذللك بالنسبة لعينة

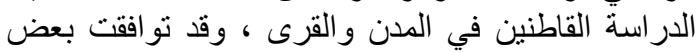

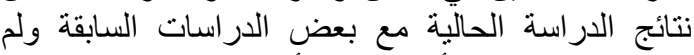

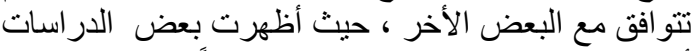

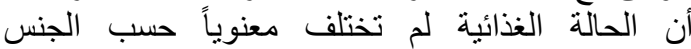
(Rist et al ,2012 Cobiac and Syrette ,1995)

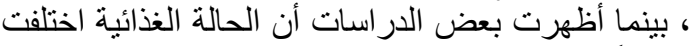

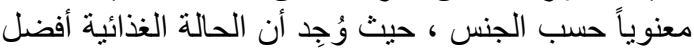

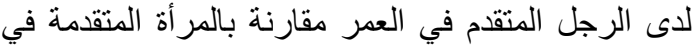

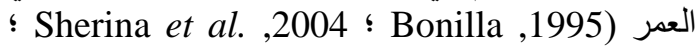
. (Buffa et al. ,2010

التوصيات : لأن مستوى سوء التغذية مرتفع بين كبار

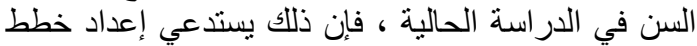

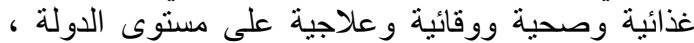

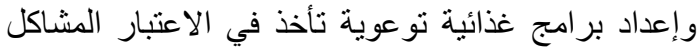

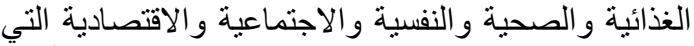

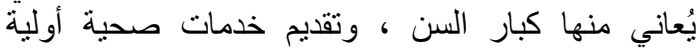
وتدريب العاملين الصحيين خاصة المسئولين عن الرئي الرعاية

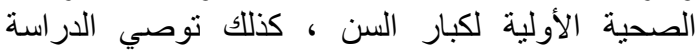
المسئولين الصحيين بإجر اء التقييم الدوري للحارئ التئة الغذائية

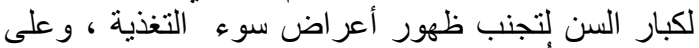

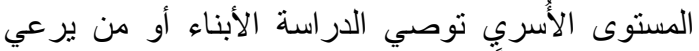

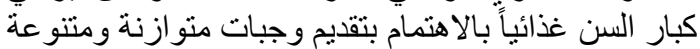

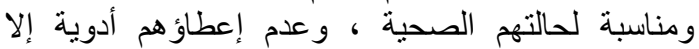

Sherina et نتائج الدر اسة الحالية تو افقت مع در اسة

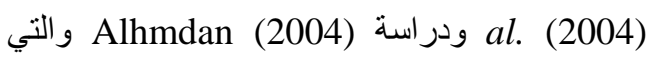
أظهرت أن هناك علاقة معنوية بين الحالة الغذائية والإصـابة بالأمراض المزمنة ، حيث بيّت كثير من الدراسات السابقة أن المتقدمين في العمر مصابون بأمر اض مزمنة مثل ضغط الدم المرتفع وتصلب الثر ايين وداء البول السكري والسمنة وحموضة المعدة ونقص بعض المغذيات (مثل الحديد و الفيتامينات) و أمر اض مزمنة أُخرى، بسبب عدة عوامل منها الممارسات الغذائية و الصحية و الحياتية السيئة (Bonilla (1995 ؛ ؛ Clarke

؛ Hengstermann et al. 2007 ؛ et al. 1998 ، (AbdelRahman ,2014 ؛ Reddy et al. ,2014 هذا بالإضافة للحالة النفسية السيئة لكبار السن التي تؤثر Engel ( سلباً على الثهية للأكل وتؤدي إلى سوء التغذية بإنهاية . (et al ,2011

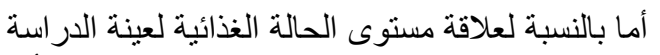

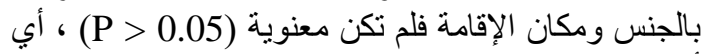

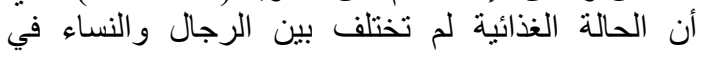


communities. (PhD.Thesis). Texas Thech. University, USA.

Buffa, R., G. Floris, M. Lodde, M. Cotza and E. Marini (2010). Nutritional status in the healthy longeval population from Sardinia (Italy). The Journal of Nutrition, Health and Aging. 14 (2) : $97-102$.

Castro-Costa, E., S. Peixoto, J. Firmo, E. Uchoa and M. Lima-Costa (2013). The association between nutritional status and cognitive impairment in Brazilian community-dwelling older adults assessed using a range of anthropometric measure- the Bambui study. Dement Neuropsychol. 7 (4) : 403 -409 .

Chung, L. and J. Chung (2014). Effectiveness of food education program improving appetite and nutritional status of elderly adults living at home. Asia Pac J. Clin. Nutr. 23 (2) : $315-320$.

Clarke, D., M. Wahlqvist and B. Strauss (1998). Undereating and undernutrition in old age: integrating bio-psychosocial aspects. Age and Ageing. $27: 527-534$.

Cobiac, L. and J. Syrette (1995). What is the nutritional status of older Australians? Proceedings of Nutrition Society of Australia. $19: 139-145$.

DiMaria-Galili, R. (2002). Changes in nutritional status and postoperative outcomes in elderly CABG patients. Biological Research for Nursing. 4 (2) : $73-84$.

Donini, L., P. Scardella, L. Piombo, B. Neri and R. Asprino, et al. (2013). Malnutrition in elderly: social and economic determinants. The Journal of Nutrition, Health and Aging. 17 (1) : $9-$ 15.

Dorner, T., E. Luger, J. Tschinderle, K. Stein, S. Haider, A. Kapan, C. Lackinger and K. Schindler (2014). Association between nutritional status (MNA $\AA$ - SF) and frailty (SHARE-FI) in acute hospitalized elderly patients. The Journal of Nutrition, Health and Aging. 18 (3) : $264-268$.

$$
\begin{aligned}
& \text { باستشارة الطبيب المعالج ، كذلك تهيئة المكان المريح لهم }
\end{aligned}
$$

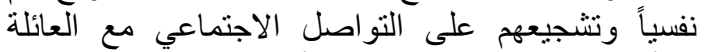

$$
\begin{aligned}
& \text { و الأصدقاء (خاصة في حال وفاة أحد الزوجين) . }
\end{aligned}
$$

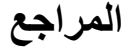

$$
\begin{aligned}
& \text { أبوسريع ، رضا عبد الله ـ (2004) ـ ـ تحليل البيانات } \\
& \text { باستخدام برنامج SPSS ـ دار الفكر ، عمان ، الأردن }
\end{aligned}
$$

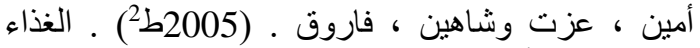

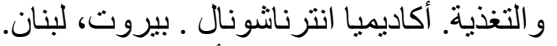

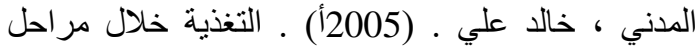

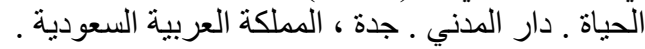

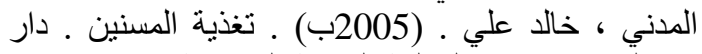

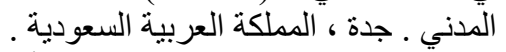

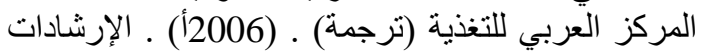

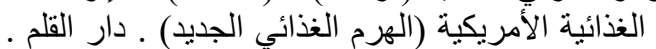

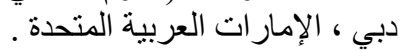

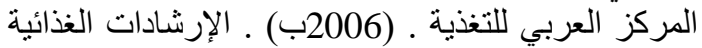

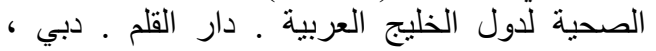

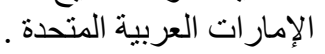

Abbott, R., R. Whear, J. Thompson-Coon, O. Ukoumunne, M. Rogers, A. Bethel, A. Hemsley and Stein (2013). Effectiveness of mealtime interventions on nutritional outcomes for the elderly living in residential care: A systematic review and meta-analysis. Ageing Research Reviews. 12 (4) : 967 - 981.

AbdelRahman, T. and N. Elkholy (2014). Prevalence of sarcopenia among nursing home older residents in Cairo, Egypt. Advances in Aging Research. $3: 118$ 123 .

Alhamdan, A. (2004). Nutritional status of Saudi male living in Riyadh nursing home . Asia Pac. J. Clin. Nutr. 13 (4) : 372 376 .

Alibhai, S., C. Greenwood and H. Payette (2005). An approach to the management of unintentional weight loss in elderly people. C.M.A.J. $15: 773-780$.

Bernstein, M. and N. Munoz (2012). Position of the Academy of Nutrition and Dietetics: Food and Nutrition for Older Adults: Promoting Health and Wellness. Journal of the Academy of Nutrition and Dietetics. 112 (8) : $1255-1277$.

Bonilla, J. (1995). Objective validation of a nutrition screening instrument in tow rural 
American Medical Directors Association. 16 (2) : $93-100$.

Kimokoti, R. and D. Hamer (2008). Nutrition, health, and aging in sub-saharan Africa. Nutrition Reviews. 66 (11) : 611 - 623 .

Kimura, M., A. Moriyasu, S. Kumagai, T. Furuna, S. Kimura and T. Suzuki (2013). Community-based intervention to improve dietary habits and promote physical activity among older adults: a cluster randomized trail. BMC Geriatrics. 13 : 8 (www.biomedcentral.com) Visit on 8/ 6 / 2017.

Kruizenga, H., J. Seidell, H. de Vet, N. Wierdsma and M. van Bokhorst (2005). Development and validation of a hospital screening tool for malnutrition: the short nutritional assessment questionnaire (SNAQC). Clinical Nutrition. 24 : 75 - 82 .

Kucukerdonmez, O., E. Koksal, N. Rakicioglu and G. Pekcan (2005). Assessment and evaluation of the nutritional status of the elderly using 2 different instruments. Saudi Med. J. 26 (10) : 1611 - 1616 .

MacLellan, D. and L. Van Til (1998). Screening community-dwelling elderly on Prince Edward Island. Canadian Journal of Public Health. 89 (5) : 342 - 346.

Patterson, A., A. Young, J. Powers, W. Brown and J. Byles (2002). Relationships between nutrition screening checklists and the health and well-being of old Australian women. Public Health Nutrition. 5 (1) : $65-71$.

Phillips, M., A. Foley, R. Barnard, E. Isenring and M. Miller (2010). Nutritional screening in community-dwelling older adults: a systematic literature review. Asia Pac. J. Clin. Nutr. 19 (3): 440 - 449.

Posner, B., A. Jette, K. Smith and D. Miller (1993). Nutrition and health risks in the elderly: the nutrition screening initiative. Am. J. Public Health. 83 : $972-978$.

Quandt, S. and D. Chao (2000). Gender Differences in nutritional risk among older rural adults. Journal of Applied Gerontology. 19 (2) : $138-150$.
Elsawy, B. and K. Higgings (2011). The geriatric assessment. Am. Fam. Physician. 83 (1) : 48 - 56 .

Engel, J., F. Siewerdt, R. Jackson, U. Akobundu, C. Wait and N. Sahyoun (2011). Hardiness, Depression, and Emotional Well-Being and Their Association with Appetite in Older Adults. Journal of the American Geriatrics Society. 59 : 482-487.

Ficklen, D., A. Manage and A. OmyemehSea (2011). Admission to an assisted living facility results in increased weight for female residents and normal-weight residents: a pilot study. Int. J. Health Nutr. 2 (2) : $14-18$.

Hengstermann, S., A. Fischer, E. Steinhagen-Thiessen and R. Schulz (2007). Nutritional status and pressure ulcer: what we need for nutritional screening. Journal of Parenteral and Enteral Nutrition. 31 (4) : $288-294$.

Jensen, G., K. Kita, J. Fish, D. Heydt and C. Frey (1997). Nutrition risk screening characteristics of rural older persons: relation to functional limitations and health care charges. Am. J. Clin. Nutr. 66 : $819-828$.

Jensen, G., J. Friedmann and C. Coleman (2001) . Screening for hospitalization and nutritional risks among communitydwelling older persons. Am. J. Clin. Nutr. $74: 201-205$.

Kamp, B. (2010). Position of the American Dietetic Association, American Society for Nutrition, and Society for Nutrition Education: Food and Nutrition Programs for Community-Residing Older Adults. Journal of the American Dietetic Association. $110: 463-472$.

Keller, H. and M. Hedely (2002). Nutritional risk needs assessment of communityliving seniors: prevalence of nutrition problems and priorities for action. Journal Community Health. 27 (2) : $121-132$.

Keller, H., A. Beck and A. Namasivayam (2015). Improving Food and Fluid Intake for Older Adults Living in Long-Term Care: A Research Agenda. Journal of the 
Georgians. (MSc.Thesis). Florida International University, USA.

Skipper, A., M. Ferguson, K. Thompson, V. Castehhanos and J. Porcari (2012). Nutritional screening tools: an analysis of the evidence. J. Parenter. Enteral Nutr. $36: 292-298$.

Small, S. (2010). Dietitians` use and perceptions of nutrition screening tools for the older adults. (MSc.Thesis). University of Kentucky, USA.

Southgate, K., H. Keller and H. Reimer (2010). Determining knowledge and behavior change after nutrition screening among older adults. Can. J. Diet Prac. Res. $71: 128-133$.

Visvanathan, R., R. Penhall and I. Chapman (2004). Nutritional screening of older people in a sub-acute care facility in Australia and its relation to discharge outcomes. Age and Aging. 33 : $260-$ 265.

Wellman, N., B. Kamp, N. Kirk-Sanchez and P. Johson (2007). Eat better and move more: a community-based program designed to improve diets and increase physical activity among older Americans. Am. J. of Public Health. 97 (4) : $710-$ 717 .

Wunderlich, S., J. Brusca, Y. JohnsonAustin and M. O'Malley (2012). Eating behaviors of older adults participating demographic backgrounds. Global Journal of Health Science. 4 (6) : $204-$ 215 .

www.abbottnutritionhealthinstiute.org-(A)

(Hafer ,N. Hospital malnutrition: assessment and intervention methods) Visit on 29 / 6 / 2014 .

www.abbottnutritionhealthinstitute.org-(B)

(DETERMINE your nutritional health) Visit on 29 / 6 / 2014.

www.cdaaa.org (DETERMINE your nutritional health) Visit on 29 / 6 / 2014 .
Reddy, N., L. Reddy, M. Pallavi, N. Reddy and P. Sireesha (2014). A study on nutritional status and prevalence of non communicable disease among the rural elderly of Tamil Nadu: a community based cross sectional study. International Journal of Research in Health Sciences. 2 (2) : $604-609$.

Reuben, D. (2004). Quality indicators for malnutrition for vulnerable communitydwelling and hospitalized older persons. Working Paper. University of California, Los Angeles, USA.

Rist, G., G. Miles and L. Karimi (2012). The presence of malnutrition in community living older adults receiving home nursing services. Nutrition and Dietetics. $69: 46$ 50 .

Ritchie, C., J. Burgio, J. Locher, A. Cornwell, D. Thomas and M. Hardin (1997). Nutritional status of urban homebound older adults. Am. J. Clin. Nutr. 66 : 815 818 .

Salehi, L., H. Eflekhar, K. Mohammad, S. Tavafian, A. Jazayery and A. Montazerie (2010). Consumption of fruit and vegetables among elderly people: across sectional study from Iran. Nutrition Journal. 9: 2 (www.nutritionjournal.com) . Visit on 8/ 6 / 2017.

Sharkey, J. and P. Haines (2002). Use of telephone-administered survey for identifying nutritional risk indicators among community-living older adults in rural areas. Journal of Applied Gerontology. 21 (3) : $385-403$.

Sherina, M., A. Rozali, M. S. Shiran and A. Sam (2004). The association of nutritional risk with physical and mental health problems among elderly in a semiurban area of Mukim Kajang, Selangor, Malaysia. Ma.I J. Nutr. 10 (2): 149 - 158.

Sinnett, S. (2009). The ability of the nutrition screening initiative determine checklist to evaluate the nutrition risk status of older 


\title{
NUTRITIONAL EVALUATION OF MIDDLE AND OLD AGE ADULTS IN RELATION TO SOME FACTORS IN AL-HASSA PROVINCE, EASTERN SAUDI ARABIA
}

\author{
Najat Ali Alabbad \\ Dep. Of Food and Nutrition Sciences, College of Agricultural and Food Sciences - \\ King Faisal University - Kingdom of Saudi Arabia
}

\begin{abstract}
Malnutrition" is one of the most important health problems facing the elderly and the most common cause of disease and death in this age group. The aim of this study is to evaluate the nutritional status of adults in middle and old age in Al-hassa Province and its relationship to some factors. The descriptive analytical approach was used, where data were collected by the distribution of Nutrition Screening Initiative (NSI). General data were collected for the sample of the study, such as gender, age, health, economic and employments status and place of residence. The sample number was 802 old persons. Data were analyzed through the statistical program SPSS, ver. 17. The results showed that the nutritional status was poor for most adults in middle and old age (67.3\%) and they had nutrition-related diseases (90.8\%), more than half of them eat low amounts of vegetables and fruits (52.4\%), had health problems (68.7\%), had oral problems and feeding difficulty (39.9\%), take 3 or more prescribed and nonprescribed medications (62.2\%), unintentionally changed their weight (44.1\%), and eat their meals lonely most of the time (40.6\%). The level of nutritional status was significant for some factors, such as age, health and work status and income level, the nutritional status was worse among those with the older age (80.6\%), low income (78.3\%), retired or housewives $(75.2 \%)$, and who had several nutrition-related diseases (73.2\%).), but there was no significant relationship between nutritional status and sex and place of residence. Based on the results, the study recommends that the elderly's caregivers pay attention to providing them balanced and varied meals suitable for their health situation, as well as creating psychologically comfortable place for them, and encouraging them to socialize with family and friends. At the Governmental level, the study recommends the importance of preparing nutritional and health preventive and therapeutic plans, and providing nutrition education programs that take into consideration the nutritional, health, psychological, social and economic problems suffered by the elderly, and provide primary health services and training to health workers, especially those responsible for primary health care for the elderly.
\end{abstract}

Key words: Nutrition Screening Initiative, nutritional evaluation in the middle and old age, Malnutrition, Chronic Diseases, Elderly, Kingdom of Saudi Arabia. 
